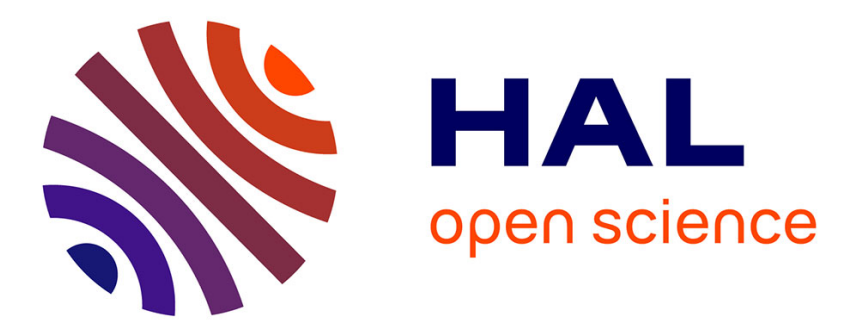

\title{
Using Mechanoluminescent Materials to Visualize Interparticle Contact Intensity in Granular Media
}

Pawarut Jongchansitto, Damien Boyer, Itthichai Preechawuttipong, Xavier Balandraud

\section{- To cite this version:}

Pawarut Jongchansitto, Damien Boyer, Itthichai Preechawuttipong, Xavier Balandraud. Using Mechanoluminescent Materials to Visualize Interparticle Contact Intensity in Granular Media. Experimental Mechanics, 2020, 60 (1), pp.51-64. 10.1007/s11340-019-00540-0 . hal-03039239

\section{HAL Id: hal-03039239 \\ https://hal.uca.fr/hal-03039239}

Submitted on 3 Dec 2020

HAL is a multi-disciplinary open access archive for the deposit and dissemination of scientific research documents, whether they are published or not. The documents may come from teaching and research institutions in France or abroad, or from public or private research centers.
L'archive ouverte pluridisciplinaire HAL, est destinée au dépôt et à la diffusion de documents scientifiques de niveau recherche, publiés ou non, émanant des établissements d'enseignement et de recherche français ou étrangers, des laboratoires publics ou privés.

\section{(c)(1)}

Distributed under a Creative Commons Attribution| 4.0 International License 


\title{
Using mechanoluminescent materials to visualize interparticle contact intensity in granular media
}

P. Jongchansitto ${ }^{1}$, D. Boyer ${ }^{2}$, I. Preechawuttipong ${ }^{1}$, X. Balandraud ${ }^{3, *}$

${ }^{1}$ Department of Mechanical Engineering, Faculty of Engineering, Chiang Mai University, 239 Huay Kaew Rd., Muang District, Chiang Mai 50200, Thailand

${ }^{2}$ Université Clermont Auvergne, CNRS, SIGMA Clermont, Institut de Chimie de ClermontFerrand (ICCF), 63000 Clermont-Ferrand, France

${ }^{3}$ Université Clermont Auvergne, CNRS, SIGMA Clermont, Institut Pascal, F-63000

Clermont-Ferrand, France

"Corresponding author. Tel.: +33 4732880 89. Fax: +33 4732881 00. E-mail address: xavier.balandraud@sigma-clermont.fr

\begin{abstract}
Mechanoluminescent materials have the property of emitting light when they are mechanically deformed. The paper deals with the potential use of these active substances to reveal interparticle contact force networks in granular media under mechanical loading. Preliminary uniaxial tensile tests were first performed on two types of longitudinal specimens for comparison purposes: pure epoxy resin and epoxy resin containing mechanoluminescent powders. Stress-strain curves showed that the powder acted as a reinforcement, but fractographic analysis by SEM revealed that debonding occurred between the epoxy matrix and powder grains during mechanical loading. Various two-dimensional cohesionless granular systems were then studied, using mechanoluminescent cylinders subjected to compression. Whereas uniaxial tensile tests featured homogeneous light emission, localized mechanoluminescence intensities were revealed in the contact zones between cylinders. The study shows that mechanoluminescent materials open perspectives for the identification of interparticle contact intensities in granular media.
\end{abstract}

Keywords: granular material; mechanoluminescence; confined compression; interparticle contact; luminescence 


\section{Introduction}

Granular materials are omnipresent in our everyday life and in many industrial fields. They are composed of grains with a wide variety of particle sizes and shapes, as well as of constitutive materials. Let us cite sands, soils and rocks in civil engineering; cereals, sugar and rice in the agro-food processing industry; or raw materials for preparing medical drugs in the pharmaceutical industry. Granular materials feature complex mechanical behaviors that differ from common solids, liquids, and gases [1]. Their macroscopic response is governed by the interaction forces transmitted through the contacts between particles. A highly inhomogeneous network of interparticle forces is a unique characteristic of discrete media subjected to a macroscopic loading [2]. This explains the wide range of phenomena observed in these materials. The influence of parameters such as particle size and shape [3-5], coefficient of friction [6], surface energy [7] and composition of mixtures [8] on the contact force network has mainly been investigated by means of numerical simulation. Some experimental approaches are also available, in particular full-field measurement techniques.

In the last few decades, non-contact full-field measurement techniques have widely spread in the mechanics of materials community, leading to important insights into the mechanical behavior of materials at a local scale. Indeed the use of cameras with suitable image processing provides a large amount of data, either at the surface of the tested material or inside the matter, complementary to macroscopic quantities from load cells or extensometers for instance. Images are captured at different stages of the mechanical loading, usually starting from the unloaded state as a reference configuration. Raw data at each pixel or voxel are related to a physical quantity depending on the camera sensor, in the visible, infrared or $\mathrm{X}$-ray ranges for instance. Quantitative thermomechanical analysis is then possible by image processing, providing data such as displacements, strains, stresses or temperatures. Full-field measurement techniques have been carried out for various types of material, but applications to discrete media remain relatively scarce compared with continuous media. This can primarily be explained by the specific loading devices that are usually required for cohesionless materials, making instrumentation by cameras a more complex process. Secondly, the intrinsically three-dimensional (3D) nature of media such as sands requires measurements in the bulk, limiting the number of techniques available: X-ray tomography combined with volumetric digital image correlation [9-11], computerized X-ray tomography $[12,13]$, flash X-ray shadowgraphy [14], magnetic resonance imaging [15, 16], radar-based 
sensing [17] and positron emission particle tracking [18]. The carbon paper method can be also considered as a measurement technique in the bulk, as it provides contact pressures in sections of 3D granular materials [19].

Despite their limitations, surface measurements have been advantageously employed for the analysis of two-dimensional (2D) granular systems, for instance composed of cylinders placed in parallel (thus forming so-called Schneebeli materials [20]). Optical imaging is usually combined with digital image correlation (DIC), such as in the particle image velocimetry (PIV) technique, in order to measure the in-plane particle displacements and then the corresponding strains of the granular organization [21-23]. Strains in deformable particles can be also assessed by DIC, see for instance Refs [24-29]. It is possible to extract interparticle forces by combining experimental strain data with Granular Element Method or Finite Element Method [27-29]. Stress fields can be also obtained from certain full-field measurement techniques. Shear stresses can be measured by photoelasticimetry using particles made of birefringent materials [30-41]. It is possible to identify contact force networks by processing the photoelastic data [42]. Beyond measurements in the visible range, infrared (IR) thermography has been employed to measure hydrostatic stress fields in granular materials by Thermoelastic Stress Analysis [43-45]. It is possible to reveal thermoelastic couplings [45] as well as material self-heating, which can mainly be attributed to interparticle friction [46-48]. In the present study, another physical principle is employed to provide information on the mechanical response of granular systems at the local scale: mechanoluminescence.

Mechanoluminescence is a physical phenomenon occurring in particular crystalline materials that are able to emit visible light in response to mechanical stimuli such as grinding, cutting, striking or friction $[49,50]$. The term can also refer to luminescence induced by elastic deformation, plastic deformation or fracture, depending on the magnitude of mechanical solicitation. Accordingly, mechanoluminescent (ML) materials can be used as sensors for structural damage, fractures and deformations [51-53]. Most ML materials correspond to inorganic compounds that are constituted of an oxide host lattice doped with lanthanide ions [54-56] or more rarely with transition metal elements [57]. Among them, $\mathrm{SrAl}_{2} \mathrm{O}_{4}:\left(\mathrm{Eu}^{2+}, \mathrm{Dy}^{3+}\right)$ (designated by SAO-ED in the following) was reported as the one exhibiting the strongest ML intensity, emitting green light upon mechanical stress [58, 59]. Several explanations have been proposed in the literature concerning the origin of mechanoluminescence [58]. The most 
accepted hypothesis for SAO-ED is that, upon UV excitation, electrons of $\mathrm{Eu}^{2+}$ are first "trapped" in crystal defects due to oxygen atom vacancies; then mechanical deformation causes the de-trapping of these electrons from deeper traps to shallow traps and then to the conduction band leading to the radiative recombination of charge carriers and thus green light emission. SAO-ED is known to exhibit a long afterglow in the green wavelength range after photonic excitation, mainly in the ultraviolet-visible range [60]. It is worth nothing that most of the above-cited references (Refs [49-58]) show images of a ML cylinder subjected to radial compression, presented as a typical case of heterogeneous distribution of stress/light. Note also that publications on ML materials are mainly in the communities of optics, physics, chemistry and material science. However, Kondo et al. recently employed a ML coating to visualize load transmission in planar granular assemblies made of glass beads [61]. They used SAOE particles mixed with an epoxy resin in paint form. Experimental methodology consisted in the preliminary photonic excitation of the ML coating before applying mechanical loading to the granular system.

In the present work, SAO-ED ML powder grains were incorporated in transparent epoxy resin to form cylinders with different diameters for compression tests, as well as dumbbell-like specimens for preliminary tensile tests. The epoxy matrix was utilized to transfer stress to the powder during mechanical loading. The objective of the study is to demonstrate the potentiality of ML materials to reveal interparticle contact intensities in 2D cohesionless granular materials. The paper is organized as follows. The next section describes the material elaboration, experimental mechanical set-up, and image processing procedure. Then preliminary tests in uniaxial tension until specimen rupture are analyzed. Finally, results of compression tests involving a few ML cylinders with different numbers of interparticle contacts are discussed in the perspective of future applications to larger numbers of particles.

\section{Materials and methods}

\section{Material elaboration}

SAO-ED ML powder, purchased from Honeywell, was incorporated into a two-component epoxy resin (RenLam CY 296 and Ren HY 516) with a powder-to-epoxy mass ratio of 1:19. The resulting viscous composite was poured into a mold with blind holes of different 
diameters (14 mm, $17 \mathrm{~mm}$ and $20 \mathrm{~mm}$ ): see Figure 1a. It is worth noting that the elaboration was quite tricky. First, obtaining a homogeneous viscous epoxy-powder mixture required vigorous mixing. Second, removal from the two-part mold after curing was difficult. Lastly, the SAO-ED ML powder is relatively expensive (some hundreds of euros per kilogram). Therefore, after preliminary tests, it was decided to first pour the viscous epoxy-powder mixture to a depth of $5 \mathrm{~mm}$, and then to carefully add pure epoxy to a depth of $45 \mathrm{~mm}$, producing cylinders of $50 \mathrm{~mm}$ in length: see Figure 1b. Finally, curing was performed in an oven at $80^{\circ} \mathrm{C}$ for 2 hours in order to speed up the polymerization process to obtain solid cylinders. At the end of the elaboration procedure, only one end of each cylinder (the last 5 $\mathrm{mm})$ was ML.

Insert here Figure 1: Material elaboration: a) mold for cylinders; b) cylinders used to create granular systems; c) mold for dumbbell-like specimens; d) non-ML and ML dumbbell-like specimens used for uniaxial tensile tests.

As indicated in the introduction section, photonic excitation of SAO-ED ML powder in the ultraviolet-visible range is also possible. Figure $1 \mathrm{~b}$ shows the light emission of the cylinders after homogeneous stimulation by natural light. Photoluminescence characterization was also performed with a Jobin-Yvon set-up consisting of a Xenon lamp operating at $400 \mathrm{~W}$ and two monochromators (Triax 550 and Triax 180) combined with a cryogenically cold chargecoupled device (CCD) camera (Jobin-Yvon Symphony LN2 series). Figure 2 shows the emission spectrum recorded at room temperature upon ultraviolet excitation at $365 \mathrm{~nm}$, exhibiting a strong and broad emission band centered around 540-550 nm (green). Note that the emission spectrum is the same from photonic or mechanical excitation, both for the powder alone and for the epoxy-powder composite specimens

Insert here Figure 2: Emission spectrum of the epoxy-(SAO-ED) composite recorded at room temperature upon ultraviolet excitation $(365 \mathrm{~nm})$.

Longitudinal specimens with dumbbell-like geometry were also prepared: see Figure 1c. The specimens' gauge zone was $2.15 \mathrm{~mm}$ in thickness and $9.9 \mathrm{~mm}$ in width. The useful length was equal to $110 \mathrm{~mm}$, see Figure 3a. Non-ML (pure epoxy) and ML (epoxy-powder composite) 
specimens were prepared. Figure 1d shows homogenous light emission in ML specimens after homogeneous excitation in the visible range.

\section{Experimental set-up}

Various mechanical configurations were considered during the study. First, ML and non-ML longitudinal specimens were tested in tension for comparison purposes. Figure 3 a shows a specimen placed in the grips of the uniaxial testing machine used ( $\pm 20 \mathrm{kN}$ Zwick). A clip-on extensometer with gauge length of $50 \mathrm{~mm}$ was employed for strain measurement. The mechanical loading consisted of successive load-unload cycles with increasing maximum force $F_{\max }$, until specimen failure: see Figure $4 \mathrm{a}$. To avoid bending in the specimen, the minimum force of each cycle was strictly positive (10\% of the maximum force). A waiting time of 30 min was respected between each cycle in order to reduce residual luminescence. No excitation of the ML specimens occurred between the different mechanical cycles. For practical constraints, the loading phase was force-controlled whereas the unloading phase was displacement-controlled, with a rate of $5 \mathrm{~N} / \mathrm{s}$ and $-0.02 \mathrm{~mm} / \mathrm{s}$ respectively.

Three configurations involving cylinders, all $50 \mathrm{~mm}$ in length, were also considered:

- Figure $3 b$ presents a schematic view of a single ML cylinder subjected to radial compression. The cylinder was $20 \mathrm{~mm}$ in diameter. The objective of the test was to analyze the light emission caused by the stress flow between the top and bottom contacts;

- Figure $3 \mathrm{c}$ shows a picture of three cylinders subjected to confined compression. Different diameters were used (14 mm, $17 \mathrm{~mm}$ and $20 \mathrm{~mm}$ ) to potentially distinguish distinct light intensities at the two cylinder-cylinder contacts;

- Figure $3 \mathrm{~d}$ shows the case of a granular media containing 15 cylinders, among which 3 are ML (14 mm, $17 \mathrm{~mm}$ and $20 \mathrm{~mm}$ in diameter). The other cylinders were composed of high-density polyethylene (HDPE), $10 \mathrm{~mm}$ in diameter. The objective of the test was to show that ML properties can be used to potentially investigate contact intensities in granular media. Although the number of cylinders here was small, it is a first step before future applications to large numbers of particles.

Mechanical loading consisted of displacement-controlled load-unload cycles with increasing maximum force $F_{\max }$ (negative) and a waiting time of $30 \mathrm{~min}$ between each cycle, see Figure 4b. 
Finally, Figure $3 \mathrm{e}$ shows an overall view of an experiment. The tests were performed in the dark (shutters closed and light off 30 min before the beginning of mechanical loading). Black boards and curtains were also placed in the close environment of the observed zone to limit parasitic light. It can be noted that the preparation of a test is quite delicate. Indeed, all the different aspects of the test must be completely planned and implemented before turning off the light: placement of the tested material in the testing machine, loading and acquisition conditions, protection against parasitic light such as computer screens, doors closed, etc. The next section addresses image acquisition conditions and post-processing.

Insert here Figure 3: Experimental set-up: a) uniaxial tensile test on a longitudinal specimen; b) schematic view of the radial compression of a ML cylinder; c) confined compression of three ML cylinders; d) confined compression of a granular system composed of ML and nonML cylinders; e) overall view of an experiment.

Insert here Figure 4: Mechanical loading applied: a) for longitudinal specimens; b) for granular systems.

\section{Acquisition conditions and image processing}

Luminescence can be analyzed using a videocolorimeter, which provides the variation over time of the emission spectrum at each pixel. For the present study, whose objective is to identify interparticle contacts, a simpler acquisition system was employed, namely a Fuji XT20 CMOS camera. The focal length of the lens used was equal to $52.5 \mathrm{~mm}$ and the aperture was opened at F-stop F/2. The size of the pixel projected on the observation plane was $57 \mu \mathrm{m}$. For all the tests in the study, the shutter speed was set to $0.5 \mathrm{~s}$ and images were acquired at a frequency of $1 \mathrm{~Hz}$ during mechanical loading. These values resulted from a compromise between measurement resolution and number of images over the loading duration, while considering practical constraints in terms of the duration of the acquisition and recording of each image by the camera. Image acquisition began four seconds before starting the loading. The first images were used to define the reference state. Temporal synchronization between image acquisition and mechanical loading was performed manually with a precision of $1 \mathrm{~s}$ (due to the image acquisition frequency) using the times at maximum loading and maximum light emission. Figure 5a shows an example of an image taken at $300 \mathrm{~N}$ for the $\mathrm{ML}$ 
longitudinal specimen. The specimen appears in green. Photographs were then converted to greyscale, as performed for instance in Ref. [62]. Matlab software was used for this purpose using the rgb2gray command, leading to pixel values between 0 (black) and 1 (white). The analysis below is based on the change in light intensity with respect to the reference configuration. The reference image was built by averaging three images captured just before starting the new load-unload cycle. The reference image was then subtracted from all the current images during loading. The output data obtained are named "change in light intensity" or simply "light emission" in the following. Displacements of the physical points during mechanical loading were not taken into account in the processing.

Insert here Figure 5: ML longitudinal specimen: a) image taken at $300 \mathrm{~N}$; b) distribution of light intensity of the reference image, taken before mechanical loading; c) distribution of light intensity at $300 \mathrm{~N}$; d) distribution of change in light intensity.

Some complementary information can be given about the image processing. The considered zone of interest was located between the two parts of the extensometer in contact with the specimen (see Figure 5a). For this zone, Figures $5 \mathrm{~b}$ and $\mathrm{c}$ show the distribution of light intensity for the reference configuration and for a current image (here at $300 \mathrm{~N}$ ) respectively. The standard deviations of these distributions are equal to 0.0113 and 0.0186 respectively. The former value is smaller than the latter thanks to the averaging operation performed to build the reference image. The standard deviation of the change in light intensity (difference between current image and reference image) is equal to 0.0198: see Figure 5d. It can be noted that the signal-to-noise ratio is low: the mean increase in light intensity is about 0.04 between the current and reference images, which is only twice the measurement resolution (0.0198). Some negative changes in light intensity can be noted in Figure 5d (see tail of distribution), which can be explained by the measurement noise.

The same analysis was performed using the green component alone, for comparison purposes with the use of the greyscale. It appeared that the measurement resolution was slightly worse (0.0251) than using the greyscale (0.0198). This can be explained by the fact that the blue channel also contains useful signal. Indeed, the spectrum in Fig. 2 shows light emission lying between $470 \mathrm{~nm}$ and $580 \mathrm{~nm}$ : blue (typically $460-500 \mathrm{~nm}$ ) is thus also involved, contrary to red (typically 620-700 nm). Although the weight of the blue is lower than that of the green in the definition of the greyscale $(0.2989 \times$ red $+0.5870 \times$ green $+0.1140 \times$ blue $)$, the former 
plays a non-negligible role. Finally, we note that the green channel was used in Kondo et al. in Ref. [61], while the greyscale was used by Du et al. in Ref. [62].

\section{Preliminary uniaxial tensile tests}

Before considering granular systems, preliminary information can be obtained from the mechanical response in uniaxial tension of the longitudinal specimens. Figure 6 shows the stress-strain curves obtained for a non-ML specimen (Figure 6a) and a ML specimen (Figure $6 b)$. The strain was calculated from the extensometer, while the stress is the ratio of the force to the initial cross-section area. The following comments can be made from these graphs. The maximum stress is higher for the ML specimen than for the non-ML specimen (14.1 MPa to be compared to $11.3 \mathrm{MPa}$ ), while ductility is lower (maximum strain of $1.06 \%$ to be compared to $1.26 \%$ ). Stiffness is also globally higher for the ML specimen. Clearly, the ML powder acted as a mechanical reinforcement.

Insert here Figure 6: Mechanical response in uniaxial tension for successive loadings with increasing maximum force: a) specimen without ML powder, i.e. pure epoxy specimen; b) ML specimen.

Figures $6 \mathrm{a}$ and $\mathrm{b}$ also reveal that the stress-strain curves are non-linear, and that residual strains progressively appeared at each load-unload cycle, both for ML and non-ML specimens. Figure 7 provides information obtained by SEM fractography analysis. Figure 7a shows pure epoxy using secondary electrons (SE) in order to inspect the topography of the specimen's fracture surface. The image features classic brittle failure mechanisms: smooth fracture surfaces with river lines with the same orientation. Figures $7 b$ and c show SE images at the same magnification for the ML specimen. Numerous ML grains are visible. This is confirmed by Figure 7d, which shows a backscattered-electron (BSE) image of the same zone as in Figure 7c, in order to reveal differences in composition and/or crystallographic structure. A strong contrast is observed between ML grains (bright) and epoxy (dark). It can also be noted that most of the ML grains are at the extremity of the lines with same orientation. This can be explained by the fact that grains are potential fracture initiation zones. Using SE and BSE, Figures $8 \mathrm{a}$ and $\mathrm{b}$ provide magnifications of the red rectangle indicated respectively in Figures $7 \mathrm{c}$ and d: matrix/grain debonding can be observed. Debonding is probably due to the 
large difference in stiffness between the two components, leading to incompatible strains at the interfaces. As a general comment, the stress transfer from the epoxy matrix to the ML grain is probably low during the loading in tension of the specimen, limiting the potential light emission of the powder. Finally, let us note that the mean distance between the ML grains was about $100 \mu \mathrm{m}$. As the size of the pixel projected on the observation plane was smaller $(57 \mu \mathrm{m})$, a $5 \times 5$ mean spatial filter was applied to the images in the following, leading to a spatial resolution of the maps equal to $5 \times 57=285 \mu \mathrm{m}$.

Insert here Figure 7: Fractography analysis by SEM of the longitudinal specimens: a) non-ML specimen; b) to d) ML specimen. Secondary electrons were used for images a to $\mathrm{c}$ whereas backscattered electrons were used for image $d$.

Insert here Figure 8: Fractography analysis by SEM of the ML longitudinal specimen. Images a, $\mathrm{c}$ and $\mathrm{d}$ were obtained using secondary electrons whereas image b was obtained using backscattered electrons.

Figure 9 shows the variation in the average light emission for the different loading stages of the ML specimen (see Figure 4a). It can be seen that light emission is not linear with respect to the applied force. For smaller forces, light emission is very low. Negative values are even measured, which can be explained by the measurement resolution of the change in light intensity between current and reference images (see Section "Acquisition conditions and processing of the images"). Then light emission increases progressively and tends to be linear for the highest forces: see D, E, F in the graph. A yield force could be defined, separating non-detectable and detectable light emission, although its value is difficult to identify (between 50 and $100 \mathrm{~N}$ ). Note that the curves tend to be linear, with the same slope, when the force exceeds the maximum force reached during the previous loading stage. This observation could be explained by the need to apply a higher force level in order to mechanically de-trap electrons in deeper traps. Indeed, for lower mechanical stimuli, only electrons captured in shallow traps will be released to produce ML. Another explanation could the powder-matrix debonding that probably occurred during the previous loading stage. Stress transfer from epoxy matrix to ML grains might thus be weaker until higher force levels (accompanied by additional debonding) are supported by the specimen, contributing to the shifts in force between the points D, E and F. Figure $9 \mathrm{~b}$ shows different fields of light emission in the zone of interest of the specimen. The distributions are homogenous, as expected for a homogeneous 
tensile test. However, the signal-to-noise ratio is low, leading to numerous negative values for $\mathrm{A}, \mathrm{B}$ and $\mathrm{C}$ in particular. It can be noted that the variation in light emission is not the same over each cycle: the curves in Figure 9a do not superimpose. This could be the consequence of damage at the interfaces between the epoxy matrix and ML grains, which progressively reduces the stresses transferred to the grains at each load-unload cycle. Finally, although the present study is focused on light emission during loading, some comments can be advanced concerning the unloading stage. Figure 10 shows the variation in light emission during a whole loading-unloading cycle for $F_{\max }=140 \mathrm{~N}$. Light emission decreased during the unloading stage, but residual light was present at the end of the cycle. This is why a waiting time should be respected before starting a new measurement. This constraint could be removed by applying continuous ultraviolet irradiation, as explained in Ref. [63], to overcome the drawback of afterglow time.

Insert here Figure 9: Light emission during the loading stages in uniaxial tension: a) variation in average light emission for the different loading stages of the ML specimen; b) maps of light emission at the maximum force of each loading phase in the zone of interest of the specimen.

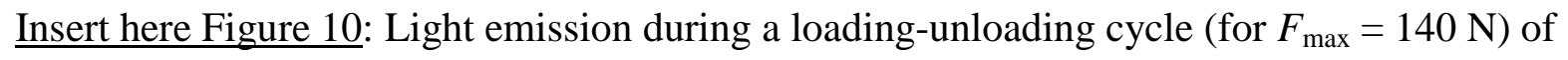
the longitudinal ML specimen in uniaxial tension.

\section{Compression test on a single cylinder}

Before considering a granular system involving several particles, the present section aims at analyzing the light emission of the considered ML material during a heterogeneous test, namely the radial compression of a cylinder (see Figure $3 \mathrm{~b}$ ). Figure 11a shows the distribution of light emission for three loadings: $F_{\max }=-500 \mathrm{~N},-600 \mathrm{~N}$ and $-700 \mathrm{~N}$. A "light tunnel" is clearly evidenced between the upper and lower contacts, with light concentrations in the contact zones. Moreover, light emission magnitude increased with loading. Figure 11b presents the average light emission over two small zones close to the contacts during the loadings: it is worth noting that the results nearly superimpose, contrary to the uniaxial tests presented in the previous section. This could be explained by less damage being caused at the matrix/grain interfaces in the case of compression. Similarly to the uniaxial tensile tests, a yield force could be defined, separating non-detectable and detectable light emission, 
although its value is also difficult to identify (about $-300 \mathrm{~N}$ ). Note, however, that uniaxial tensile tests revealed ML specimens about $30 \%$ stiffer than non-ML specimens, see Fig. 6. In the case of cylinders of which only a part is ML $(5 \mathrm{~mm}$, for a total length of $50 \mathrm{~mm})$, the external pressure applied to the ML part can be considered as also about $30 \%$ greater than that applied to the non-ML part.

The question of the type of stress involved in mechanoluminescence has already been discussed in the literature from comparisons with finite element simulations. For instance, Refs [50, 64] compared simulated maps of various stress components with maps of light emission. A similar approach was adopted in the present study: Figure 12 shows the results of a finite element simulation for purposes of comparison with the experimental results. Simulation was performed under the hypothesis of plane stress. Isotropic linear elasticity was assumed, even though non-linearity was evidenced in uniaxial tension (see Figure 6b), for the sake of simplicity. Three types of stress are mapped and compared with the light emission distribution in Figure 11a-I. It can be claimed that the light emission is not related to the hydrostatic stress. Indeed, the distribution of the sum of principal stresses features a diabolo pattern (see orange color) contrary to the experimental image. Light emission appears to be related to the shear stress, as noted in Refs [50,64], although it could be also attributed to the Von Mises stress.

Insert here Figure 11: Radial compression of a ML cylinder: a) maps of light emission for three loadings: $F_{\max }=-500 \mathrm{~N},-600 \mathrm{~N}$ and $-700 \mathrm{~N}$; b) variation in average light emission over two small zones close to the contacts during the loadings.

Insert here Figure 12: Radial compression of a cylinder: comparison between finite element simulation and experimental result.

\section{Granular systems under confined compression}

Two granular systems involving more than one cylinder and more than two contacts per cylinder are now analyzed. The objective is to distinguish distinct light emissions at the interparticle contacts as a consequence of distinct contact forces (expected especially in polydisperse granular systems). First, Figure 13a presents the light emission map obtained by 
applying a vertical compression force $F_{\max }$ of $-700 \mathrm{~N}$ to the three ML cylinders shown in Figure 3c. In the following, cylinders $14 \mathrm{~mm}, 17 \mathrm{~mm}$ and $20 \mathrm{~mm}$ in diameter are indicated by $\mathrm{S}$ (small), M (medium) and L (large) respectively. It can be noticed that the light emission at the S-M contact is greater than the light emission at the S-L contact. This result is quite logical. Indeed, the normal of the S-M contact is slightly better aligned with the vertical applied force than the normal of the S-L contact: more force is transferred from S to $\mathrm{M}$ than from $S$ to L. Moreover, stresses tend to increase when the dimensions decrease, everything else being equal. In addition, the stress flow is more clearly evidenced in the smallest cylinder (S). Figure $13 \mathrm{~b}$ shows the variation in mean light emission in the contact zones as a function of the applied vertical force. Data were extracted as the average values over the small blue zones on either side of the contact (see image). It can be observed that the light emission of the S-L contact (in red) is lower than that of the S-M contact (in black), even if there are significant fluctuations over the course of the loading. A change in slope can be noted in the graph at about $-450 \mathrm{~N}$. It could be due to a yield separating non-detectable and detectable light emission as indicated above. But, similarly to the situation of figure 3-d in Ref. [62] in a different context, the first slope could be related to a tribology effect (triboluminescence) accompanying the formation of the (frictional) contact between the cylinders. Figures $13 \mathrm{c}$ and d show zooms in the S-L and S-M contact zones respectively, for two external force levels $\left(F_{\max }=-500 \mathrm{~N}\right.$ and $\left.-700 \mathrm{~N}\right)$ using the same color scale as in Figure 13a. Clearly, the higher the applied external vertical force, the greater the light emission. As a conclusion, mechanoluminescence appears to provide coherent qualitative information about contact stress intensity between the cylinders.

Insert here Figure 13: Confined compression of three ML cylinders: a) light emission under $F_{\max }=-700 \mathrm{~N}, \mathrm{~b}$ ) variation in average light emission in the cylinder-cylinder contact zones during compression as a function of the vertical force until $F_{\max }=-700 \mathrm{~N}$, c) close-up of the contact zone between small-medium cylinders, d) close-up of the contact zone between smalllarge cylinders,

As a final case, Figure 14 considers a more complex configuration of fifteen cylinders, among which three are ML (see "Experimental set-up" section and Figures 3d and e). Figure 14a shows the reference image considered to measure changes in light intensity. Two comments can be made regarding this image: 
- non-ML cylinders are slightly illuminated by the ML cylinders due to the residual luminescence of the latter. This means that at any time, the measured light at a given ML material point is the sum of its own light emission due to the local stress and of the light coming from the immediate ML environment. Suitable image processing should be considered to remove the part due to the surrounding ML light, but this is out of the scope of the present study. Note, however, that in this context the fact that only one end of the ML cylinders (the last $5 \mathrm{~mm}$ ) was actually ML is expected to be advantageous, by reducing the light in the entire set-up;

- several contacts can be identified from this image. For instance, cylinder $\mathrm{S}$ is in contact with 6 cylinders, while cylinders $\mathrm{M}$ and $\mathrm{L}$ are both in contact with 4 other cylinders. However, this does not mean that all the contacts transfer forces under macroscopic loading. Similarly, although two cylinders appear to be in contact with the horizontal top plate, it is not possible to know a priori how the loading is distributed between them. Indeed, any infinitesimal difference in the location of these two cylinders with respect to the plate leads to large variations in the distribution of forces. Some responses can be obtained from the light emission at the contacts, as explained in the next paragraph.

Figure 14b shows the distribution of light emission for a vertical force of $-1500 \mathrm{~N}$. The following comments can be made concerning this figure, in which non-ML cylinders are numbered from \#1 to \#12 for identification purposes:

- although cylinder S was in contact with six cylinders, it was actually subjected to three active contacts. By "active contact", we mean a contact that transfers significant forces. There was a strong light emission at the contacts with cylinders \#11, L and M. No light emission was detected at the contacts with cylinders \#6, \#7 and \#10, meaning that the corresponding forces are below the yield force separating non-detectable and detectable light emission;

- the non-detection of forces between $S$ and \#6 and between $S$ and \#7 is probably due to the orientation of the corresponding contact normals: the latter were nearly perpendicular to the macroscopic vertical force. The non-detected force between $S$ and \#10 is probably due to the fact that cylinder \#10 was not "really" in contact with the horizontal plate. In other words, cylinders \#10 and \#11 were not perfectly aligned with the horizontal top plate: the latter touched "first" cylinder \#11. Thus cylinder \#10 did not transfer significant force to cylinder $S$; 
- the four contacts of cylinder L were all accompanied by light emission. Main force transfer is observed through opposite contacts L/S and L/\#1, while L/\#5 and L/\#2 contact force intensities were weaker;

- cylinder $\mathrm{M}$ featured three active contacts (M/S, M/\#3 and M/\#8), although the fourth contact (M/\#7) was accompanied by weak light emission. However, surface defects prevent further analysis (see for example the small black area in the center of the cylinder).

This example opens perspectives for the experimental analysis of granular materials with larger numbers of particles, as discussed in the conclusion section.

Insert here Figure 14: Confined compression of fifteen cylinders among which three are ML: a) reference configuration; b) light emission under $-1500 \mathrm{~N}$.

\section{Conclusion}

The study showed that mechanoluminescence is a physical phenomenon that could be used advantageously for the micromechanical analysis of granular materials:

- mechanoluminescence could be used to evidence the so-called "strong" network in granular systems. Let us recall that the distribution of interparticle contacts is usually split into a strong network and a weak network as a function of the contact force intensity [45]. The strong network supports the main part of the externally applied loading, while the role of the weak network is only to sustain system equilibrium. Identifying the strong network is useful for the understanding of the mechanical response of granular materials;

- it is well known that the contact force network is strongly impacted by any slight local fluctuation in the material properties of the particles, and in their shapes and dimensions, as well as in the boundary conditions, making it difficult to compare experimental results with simulation results using discrete element methods at a local scale. Mechanoluminescence appears to be a simple way of identifying active contacts, information that could then be implemented in simulations.

Although the number of cylinders in the present study was small, applications to much larger numbers of particles can be envisaged. 


\section{Acknowledgements}

The authors gratefully acknowledge the Ministère de l'Europe et des Affaires Etrangères (MEAE) and the Ministère de l'Enseignement supérieur, de la Recherche et de l'Innovation (MESRI) in France, as well as the Office of the Higher Education Commission (OHEC) of the Ministry of Education in Thailand. The authors also gratefully thank the French Embassy in Thailand and Campus France for their support during this research (PHC SIAM 2018, Project 40710SE). Dr. P. Jongchansitto would also like to acknowledge the financial support through the Research Grant for New Scholar (MRG6080251) from the Thailand Research Fund (TRF) and Thailand's Office of the Higher Education Commission (OHEC). Finally, the authors gratefully thank Mr Maël Tissier, Sigma-Clermont Engineering School, for the elaboration of mechanoluminescent materials, as well as Mr Clément Weigel and Mr Alexis Gravier, SigmaClermont Engineering School, for the manufacturing of the testing device and the molds.

\section{References}

[1] Jaeger HM, Nagel SR (1996) Granular solids, liquids, and gases. Rev Mod Phys 68: $1259-1272$

[2] Ostojic S, Somfai E, Nienhuis B (2006) Scale invariance and universality of force networks in static granular matter. Nature 439: 828-830

[3] Nguyen DH, Azéma E, Radjai F, Sornay P (2014) Effect of size polydispersity versus particle shape in dense granular media. Phys Rev E 90: 012202

[4] Peña AA, García-Rojo R, Herrmann HJ (2007) Influence of particle shape on sheared dense granular media, Granul Matter 9: 279-291

[5] Nouguier-Lehon C, Cambou B, Vincens E (2003) Influence of particle shape and angularity on the behaviour of granular materials: a numerical analysis. Int J Numer Anal Methods Geomech 27: 1207-1226

[6] Bardenhagen SG, Brackbill JU, Sulsky D (2000) Numerical study of stress distribution in sheared granular material in two dimensions. Phys Rev E 62:3882-3890

[7] Preechawuttipong I, Peyroux R, Radjai F, Rangsri W (2007) Static states of cohesive granular media. J Mech Sci Technol 21: 1957-1963

[8] Jongchansitto P, Preechawuttipong I, Balandraud X, Grédiac M (2017) Numerical investigation of the influence of particle size and particle number ratios on texture and force transmission in binary granular composites. Powder Technol 308: 324-333 
[9] Wolf H, Konig D, Triantafyllidis T (2003) Experimental investigation of shear band patterns in granular material. J Struct Geol 25: 1229-1240

[10] Hall SA, Bornert M, Desrues J, Pannier Y, Lenoir N, Viggiani G, Besuelle P (2010) Discrete and continuum analysis of localised deformation in sand using X-ray $\mu \mathrm{CT}$ and volumetric digital image correlation. Geotechnique 60: 315-322

[11] Hu ZX, Du YJ, Luo HY, Zhong B, Lu HB (2014) Internal deformation measurement and force chain characterization of mason sand under confined compression using incremental digital volume correlation. Exp Mech 54: 1575-1586

[12] Khalili MH, Brisard S, Bornert M, Aimedieu P, Pereira JM, Roux JN (2017) Discrete digital projections correlation: a reconstruction-free method to quantify local kinematics in granular media by X-ray tomography. Exp Mech 57: 819-830

[13] Hurley RC, Hall SA, Wright JP (2017) Multi-scale mechanics of granular solids from grain-resolved X-ray measurements. Proc R Soc A 473: 20170491

[14] Park H, Chen WNW (2012) Two orthogonal layers of metal medium in granular materials for 3D speckle shadowgraph by flash X-ray. Exp Mech 52: 1173-1177

[15] Nakagawa M, Altobelli SA, Caprihan A, Fukushima E, Jeong EK (1993) Non-invasive measurements of granular flows by magnetic resonance imaging. Exp Fluids 16: 54-60

[16] Sanfratello L, Fukushima E, Behringer RP (2009) Using MR elastography to image the 3D force chain structure of a quasi-static granular assembly. Granular Matter 11: 1-6

[17] Hill KM, Fan Y, Zhang J, Van Niekerk C, Zastrow E, Hagness SC, Bernhard JT (2010) Granular segregation studies for the development of a radar-based three-dimensional sensing system. Granular Matter 12: 201-207

[18] Parker DJ, Dijkstra AE, Martin TW, Seville JPK (1997) Positron emission particle tracking studies of spherical particle motion in rotating drums. Chem Eng Sci 52: 20112022

[19] Mueth DM, Jaeger HM, Nagel SR (1998) Force distribution in a granular medium. Phys Rev E 57: 3164-3169

[20] Schneebeli G (1956) Une analogie mécanique pour les terres sans cohésion. C R Hebd. Acad Sci 243:125-126

[21] Slominski C, Niedostatkiewicz M, Tejchman J (2007) Application of particle image velocimetry (PIV) for deformation measurement during granular silo flow. Powder Techn 173: 1-18

[22] Hall SA, Wood DM, Ibraim E, Viggiani G (2010) Localised deformation patterning in 2D granular materials revealed by digital image correlation. Granular Matter 12: 1-14 
[23] Richefeu V, Combe G, Viggiani G (2012) An experimental assessment of displacement fluctuations in a 2D granular material subjected to shear. Geotechnique Lett 2: 113-118

[24] Karanjgaokar N, Ravichandran G (2015) Experimental inference of inter-particle forces in granular systems using digital image correlation. In: Jin H, Sciammarella C, Yoshida $\mathrm{S}$ et al (eds) Advancement of optical methods in experimental mechanics, Vol 3. Conference Proceedings of the Society for Experimental Mechanics Series, Greenville, SC, USA, June 02-05, 2014. Springer, Berlin, pp 379-385

[25] Karanjgaokar N, Ravichandran G (2016) Study of energy contributions in granular materials during impact. In: Song B, Lamberson L, Casem D et al (eds) Dynamic behavior of materials, Vol 1. Conference Proceedings of the Society for Experimental Mechanics Series, Costa Mesa, CA, USA, June 08-11, 2015. Springer, New York, pp 199-204

[26] Marteau E, Andrade JE (2017) A novel experimental device for investigating the multiscale behavior of granular materials under shear. Granular Matter 19: 77

[27] Hurley R, Marteau E, Ravichandran G, Andrade JE (2014) Extracting inter-particle forces in opaque granular materials: Beyond photoelasticity. J Mech Phys Solids 63: $154-166$

[28] Hurley RC, Lim KW, Ravichandran G, Andrade JE (2016) Dynamic inter-particle force inference in granular materials: method and application. Exp Mech 56: 217-229

[29] Karanjgaokar N (2017) Evaluation of energy contributions using inter-particle forces in granular materials under impact loading. Granular Matter 19: 36

[30] Shukla A, Damania C (1987) Experimental investigation of wave velocity and dynamic contact stresses in an assembly of disks. Exp Mech 27: 268-281

[31] Roessig KM, Foster JC, Bardenhagen SG (2002) Dynamic stress chain formation in a two-dimensional particle bed. Exp Mech 42: 329-337

[32] Zhang J, Majmudar TS, Sperl M, Behringer RP (2010) Jamming for a 2D granular material. Soft Matter 6: 2982-2991

[33] Bigoni D, Noselli G (2010) Localized stress percolation through dry masonry walls. Part I-Experiments. Eur J Mech A-Solids 29: 291-298

[34] Zhang J, Majmudar TS, Tordesillas A, Behringer RP (2010) Statistical properties of a 2D granular material subjected to cyclic shear. Granular Matter 12: 159-172

[35] Wood DM, Lesniewska D (2011) Stresses in granular materials. Granular Matter 13: $395-415$ 
[36] Lesniewska D, Wood DM (2011) Photoelastic and photographic study of a granular material. Geotechnique 61: 605-611

[37] Guo P (2012) Critical length of force chains and shear band thickness in dense granular materials. Acta Geotechnica 7: 41-55

[38] Estep J, Dufek J (2012) Substrate effects from force chain dynamics in dense granular flows. J Geophys Res: Earth Surf 117: F01028

[39] Zhang L, Cai SX, Hu ZP, Zhang J (2014) A comparison between bridges and forcechains in photoelastic disk packing. Soft Matter 10: 109-114

[40] Coulais C, Behringer RP, Dauchot O (2014) How the ideal jamming point illuminates the world of granular media. Soft Matter 10: 1519-1535

[41] Mirbagheri SA, Ceniceros E, Jabbarzadeh M, McCormick Z, Fu HC (2015) Sensitively photoelastic biocompatible gelatin spheres for investigation of locomotion in granular media. Exp Mech 55: 427-438

[42] Majmudar TS, Behringer RP (2005), Contact force measurements and stress-induced anisotropy in granular materials. Nature 435: 1079-1082

[43] Chaiamarit C, Balandraud X, Preechawuttipong I, Grédiac M (2015) Stress network analysis of 2D non-cohesive polydisperse granular materials using infrared thermography. Exp Mech 39: 761-769

[44] Jongchansitto P, Balandraud X, Grédiac M, Beitone C, Preechawuttipong I (2014) Using infrared thermography to study hydrostatic stress networks in granular materials. Soft Matter 10: 8603-8607

[45] Jongchansitto P, Preechawuttipong I, Balandraud X, Grédiac M (2017) Numerical investigation of the influence of particle size and particle number ratios on texture and force transmission in binary granular composites. Powder Techn 308: 324-333

[46] Jongchansitto P, Balandraud X, Preechawuttipong I, Le Cam JB, Garnier P (2018) Thermoelastic couplings and interparticle friction evidenced by infrared thermography in granular materials, Exp Mech 58: 1469-1478

[47] Luong MP (1986) Characteristic threshold and infrared vibrothermography of sand. Geotech Testing J 9: 80-86

[48] Luong MP (2007) Introducing infrared thermography in soil dynamics. Infrared Phys Techn 49: 306-311

[49] Bünzli JCG, Wong KL (2018) Lanthanide mechanoluminescence. J Rare Earth 36: 1-41

[50] Feng A, Smet PF (2018) A review of mechanoluminescence in inorganic solids: compounds, mechanisms, models and applications. Materials 11: 484 
[51] Kamimura S, Yamada H, Xu CN (2012) Development of new elasticoluminescent material SrMg2(PO4)2:Eu. J Lumin 132: 526-530

[52] Zhang JC, $\mathrm{Xu}$ CN, Long YZ (2013) Elastico-mechanoluminescence in CaZr(PO4)2:Eu2+ with multiple trap levels. Opt Express 21: 13699-13709

[53] Zhang JC, Xu CN, Kamimura S, Terasawa Y, Yamada H, Wang X (2013). An intense elastico-mechanoluminescence material CaZnOS:Mn2+ for sensing and imaging multiple mechanical stresses. Opt Express 21, 12976-12986

[54] Zhang HW, Yamada H, Terasaki N, Xu CN (2008) Blue light emission from stressactivated CaYA13O7:Eu. J Electrochem Soc 155: J128-J131

[55] Zhang H, Terasaki N, Yamada H, Xu CN (2009) Mechanoluminescence of Europiumdoped $\operatorname{SrAMgSi}(2) \mathrm{O}(7)$ (A = Ca, Sr, Ba). Jpn J Appl Phys 48: 04C109

[56] Zhang JC, Fan XH, Yan X, Xia F, Kong WJ, Long YZ, Wang XS (2018) Sacrificing trap density to achieve short-delay and high-contrast mechanoluminescence for stress imaging. Acta Mater 152: 148-154

[57] Tu D, Xu CN, Fujio Y, Yoshida A (2015) Mechanism of mechanical quenching and mechanoluminescence in phosphorescent CaZnOS:Cu. Light-Sci Appl 4: e356

[58] Yun GJ, Rahimi MR, Gandomi AH, Lim GC, Choi JS (2013) Stress sensing performance using mechanoluminescence of SrAl2O4:Eu (SAOE) and SrAl2O4:Eu, Dy (SAOED) under mechanical loadings. Smart Mater Struct 22: 055006

[59] Yang Y, Zheng SH, Fu XY, Zhang HW (2018) Remote and portable mechanoluminescence sensing system based on a SrAl2O4:Eu,Dy film and its potential application to monitoring the safety of gas pipelines. Optik 158: 602-609

[60] Li Y, Gecevicius M, Qiu JR (2016) Long phosphorescent phosphors-from fundamentals to applications. Chem Soc Rev 45: 2090-2136

[61] Kondo A, Takano D, Kohama E, Bathurst RJ (2019) Visualization and measurement of load transmission in granular assemblies using mechanoluminescent-coated particles. Granular Matter 21:50

[62] Du Y, Jiang Y, Sun T, Zhao J, Huang B, Peng D, Wang F (2019) Mechanically excited multicolor luminescence in lanthanide ions. Adv Mater 31:e1807062

[63] Mao QN, Chen ZA, Ji ZG, Xi JH (2017) UV-assisted mechanoluminescence properties of SrAl2O4:(Eu,Dy) for impact sensing. J Mater Sci 52: 8370-8376

[64] Wang WX, Matsubara T, Takao Y, Imai Y, Xu CN (2009) Visualization of stress distribution using smart mechanoluminescence sensor. In: Lu J (ed) Advanced Materials Science and Technology. 6th International Forum on Advanced Material Science and 
Technology, Honk Kong, June 12-14, 2008. Materials Science Forum. Trans Tech Publication Ltd, Switzerland. Vol 614, pp 169-174 
a)

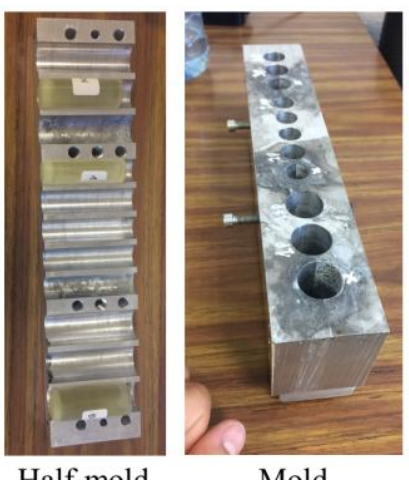

Half-mold

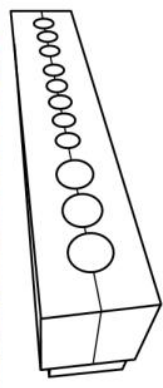

Mold b)
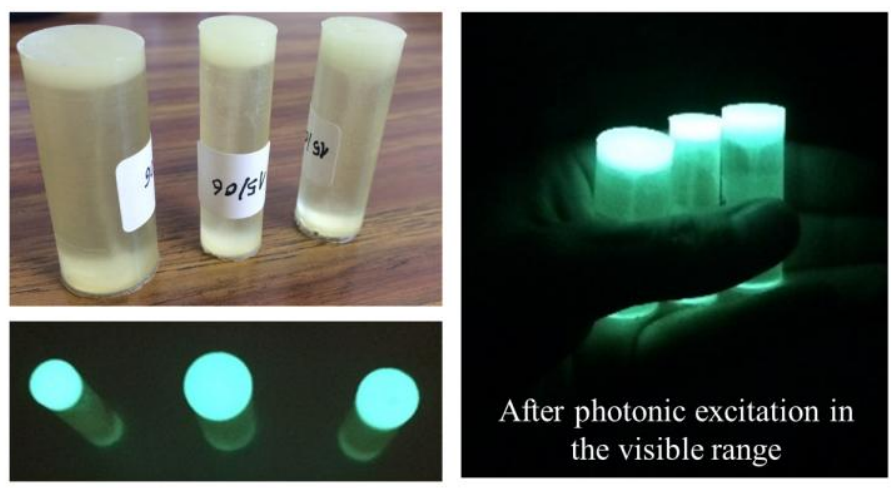

c)
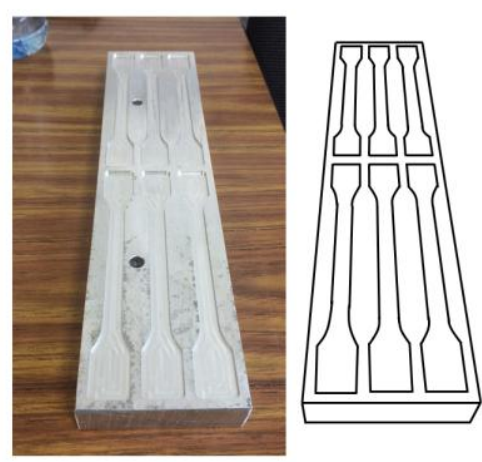

d)
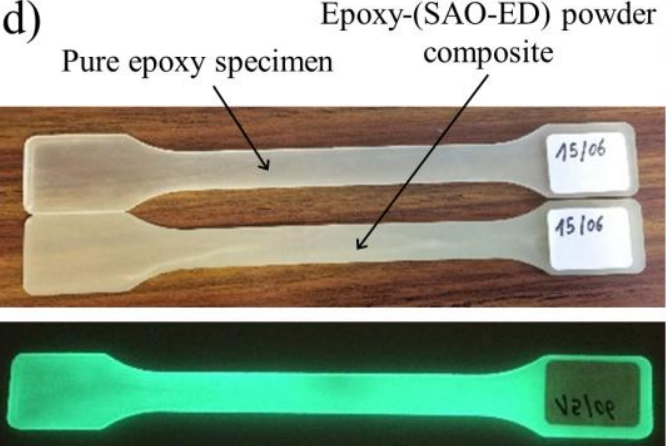

Figure 1 Material elaboration: a) mold for cylinders; b) cylinders used to create granular systems; c) mold for dumbbell-like specimens; d) non-ML and ML dumbbell-like specimens used for uniaxial tensile tests. 


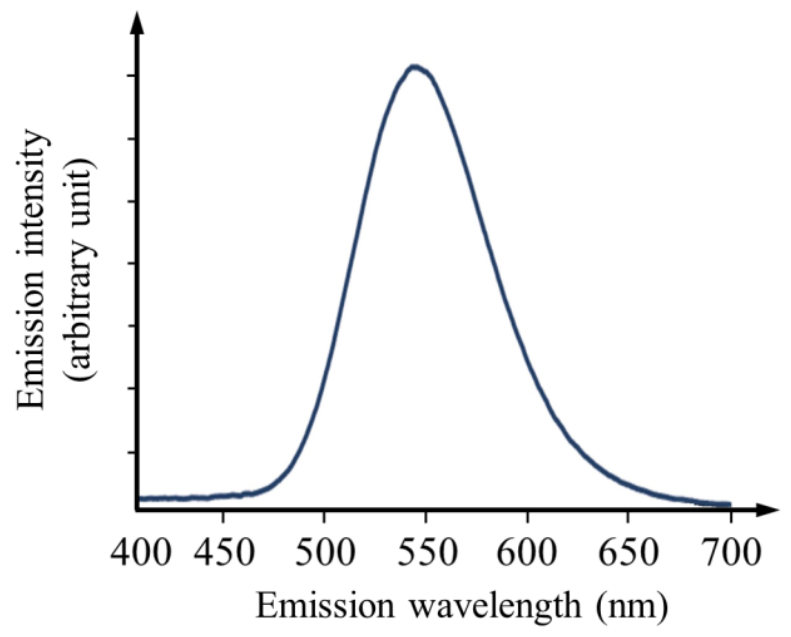

Figure 2 Emission spectrum of the epoxy-(SAO-ED) composite recorded at room temperature upon ultraviolet excitation $(365 \mathrm{~nm})$. 
a)

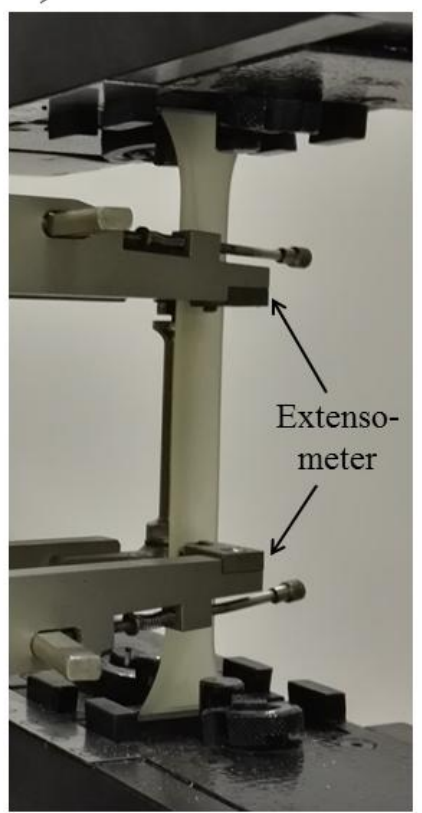

d)

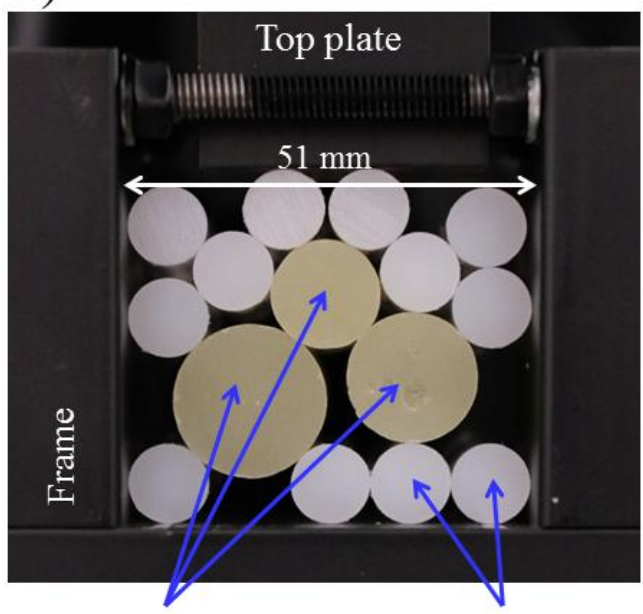

ML cylinders Non-ML cylinders

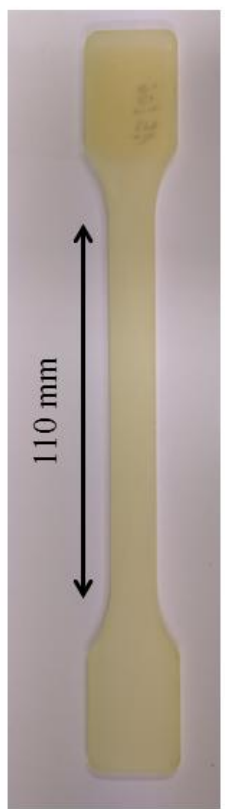

b)

Frame (clamped to the fixed grip)

c)

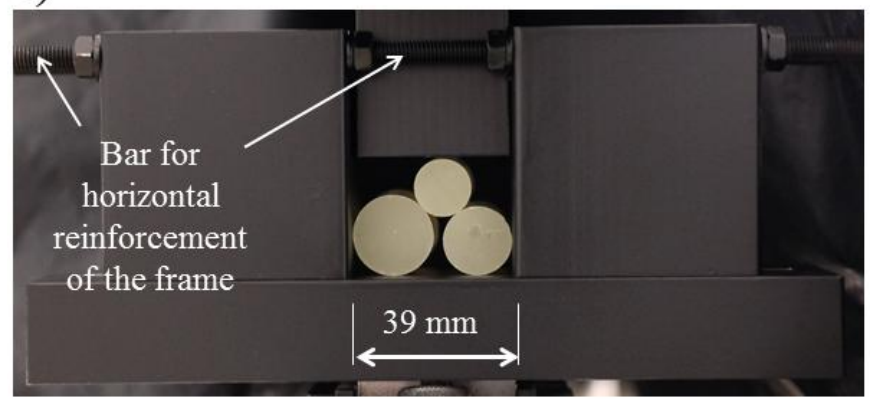

e)

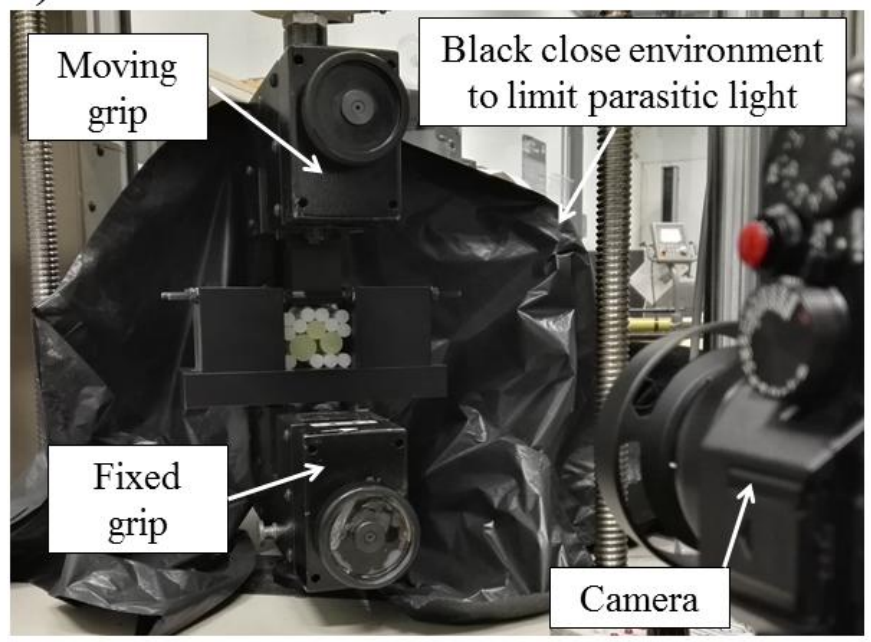

Figure 3 Experimental set-up: a) uniaxial tensile test on a longitudinal specimen;

b) schematic view of the radial compression of a ML cylinder; c) confined compression of three ML cylinders; d) confined compression of a granular system composed of ML and nonML cylinders; e) overall view of an experiment. 


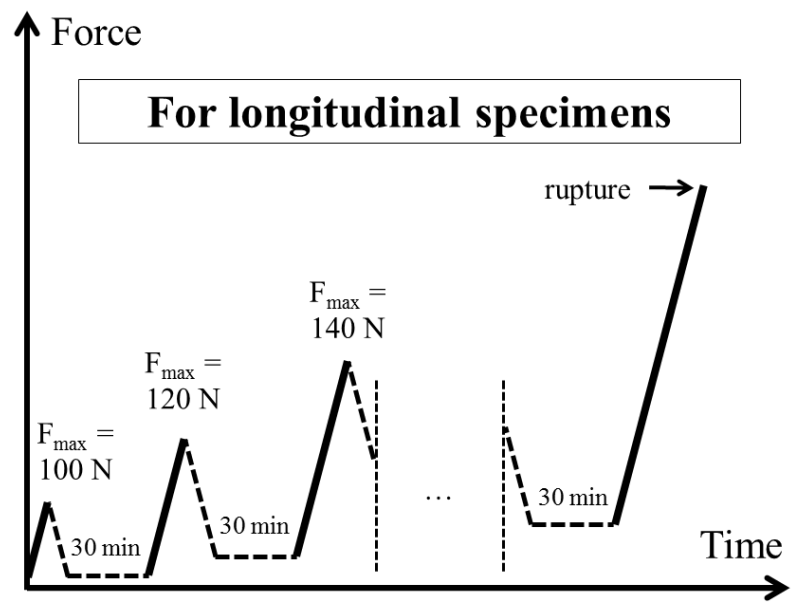

a)

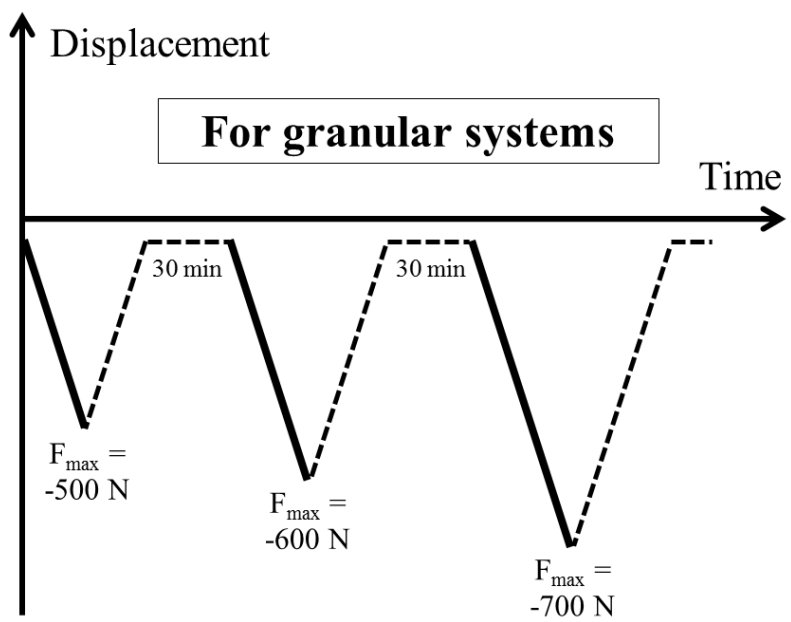

b)

Figure 4 Mechanical loading applied: a) for longitudinal specimens; b) for granular systems. 


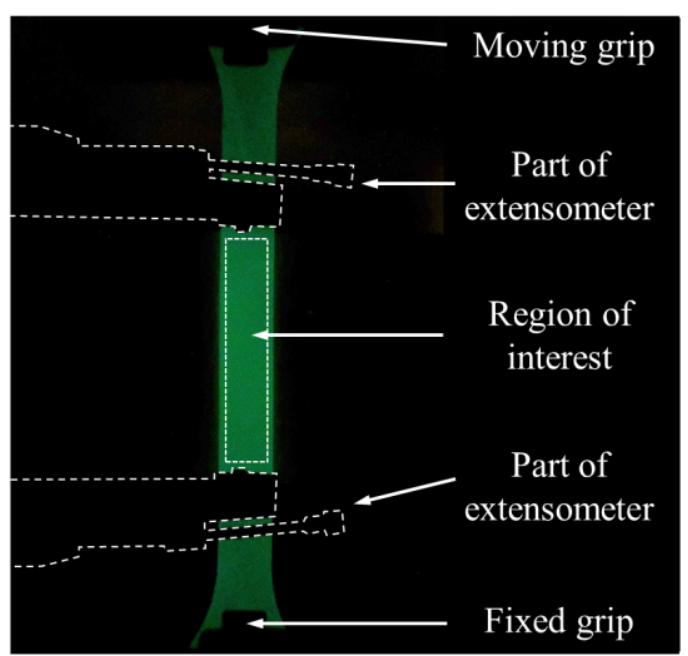

a)

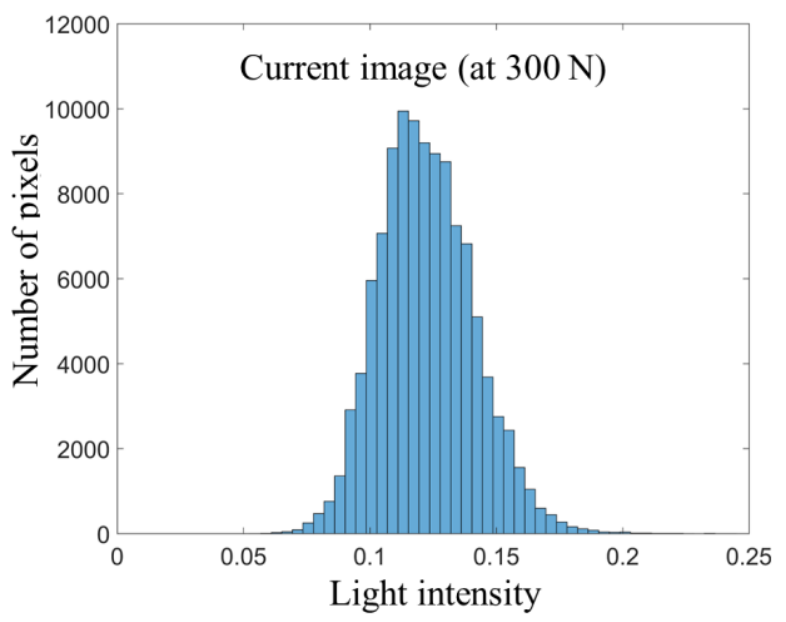

c)

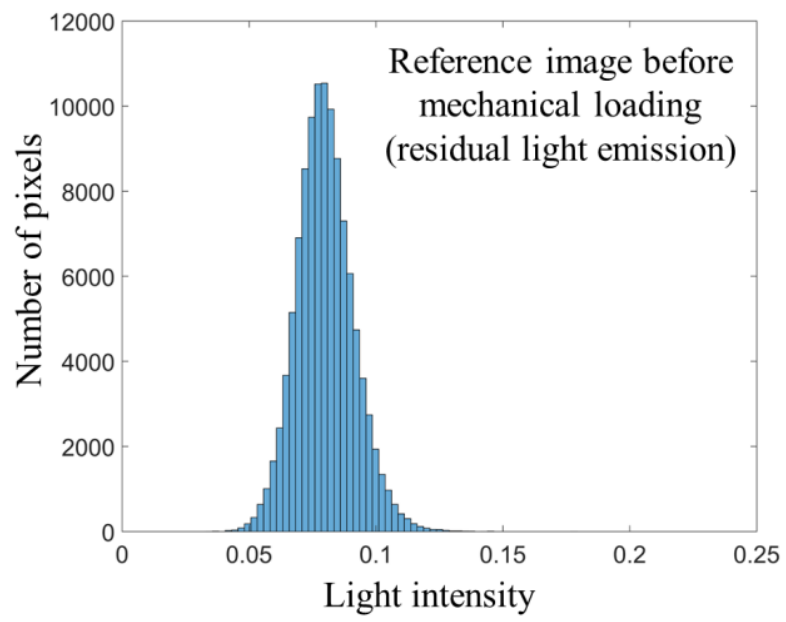

b)

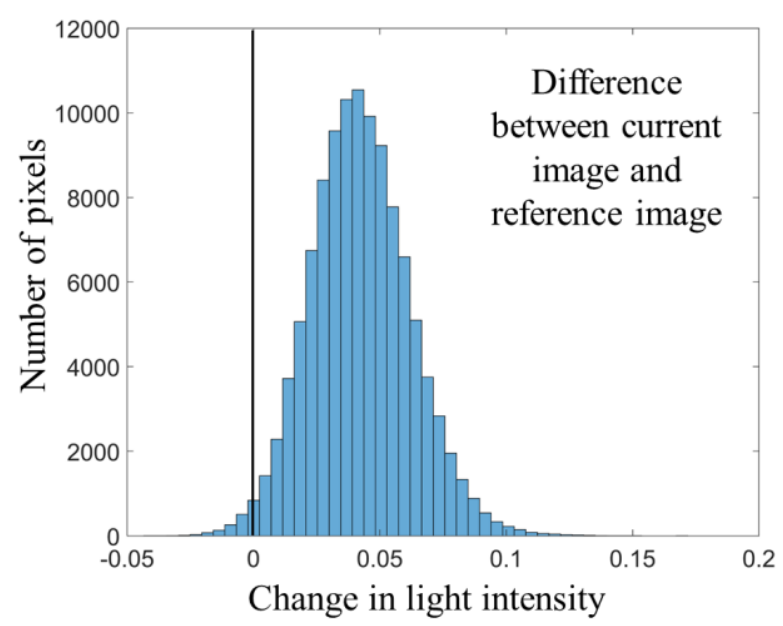

d)

Figure 5 ML longitudinal specimen: a) image taken at $300 \mathrm{~N}$; b) distribution of light intensity of the reference image, taken before mechanical loading; c) distribution of light intensity at $300 \mathrm{~N}$; d) distribution of change in light intensity. 

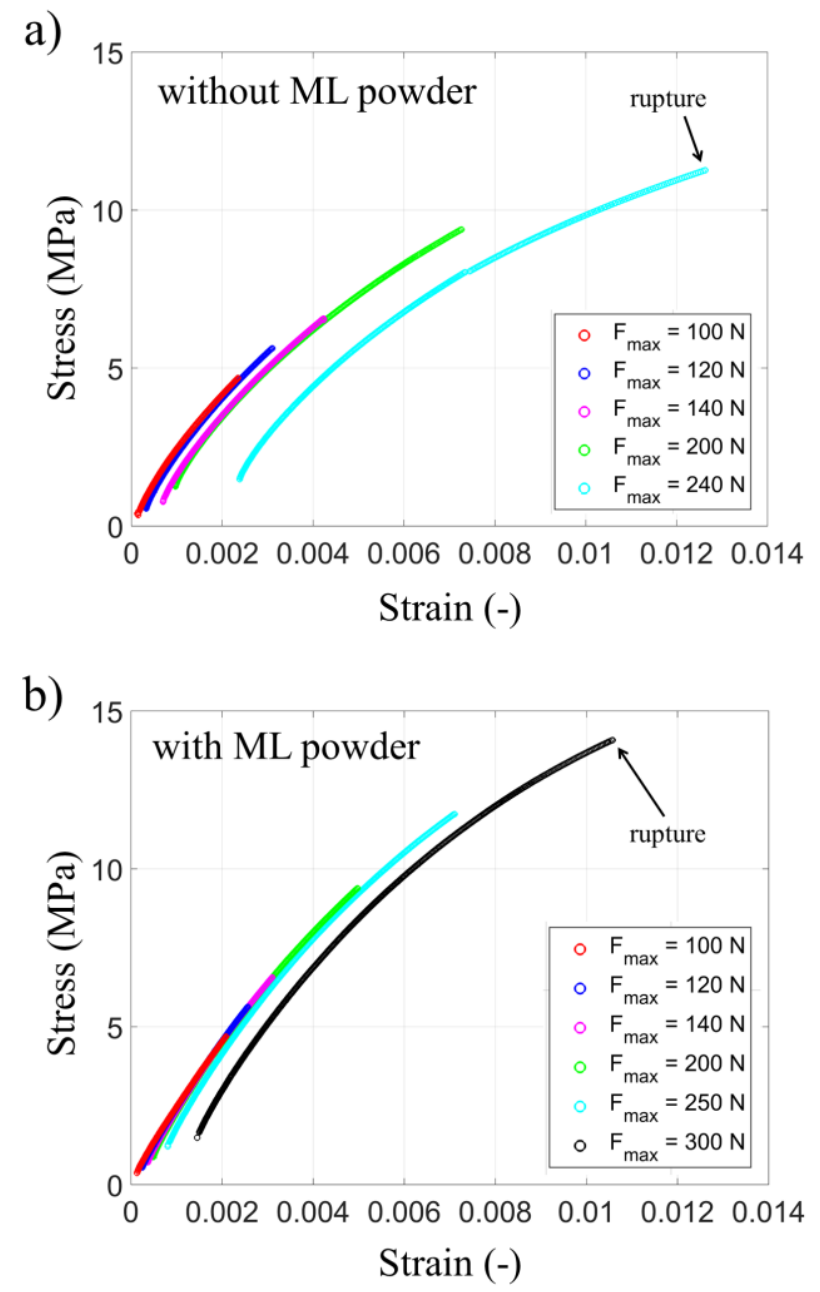

Figure 6 Mechanical response in uniaxial tension for successive loadings with increasing maximum force: a) specimen without ML powder, i.e. pure epoxy specimen; b) ML specimen. 


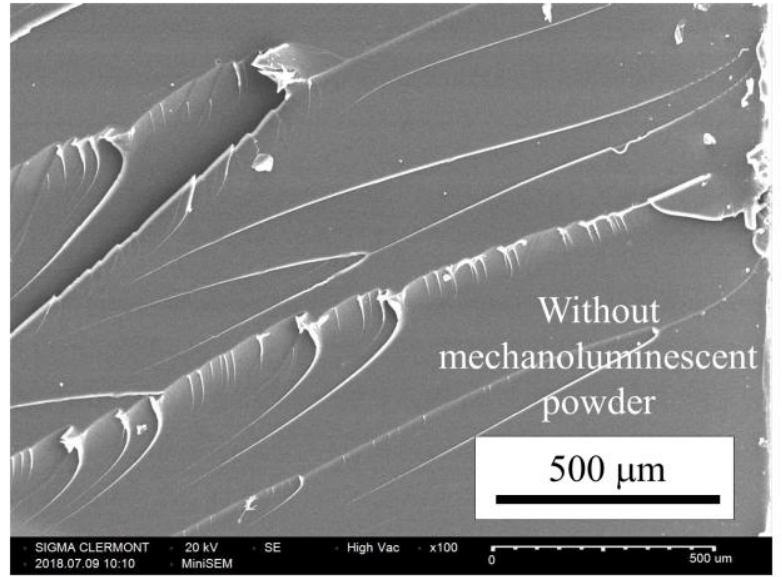

a)

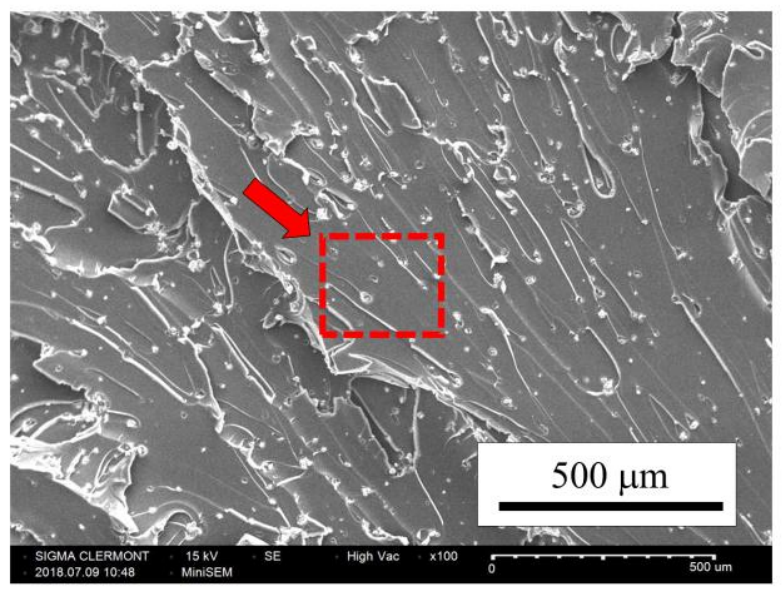

c)

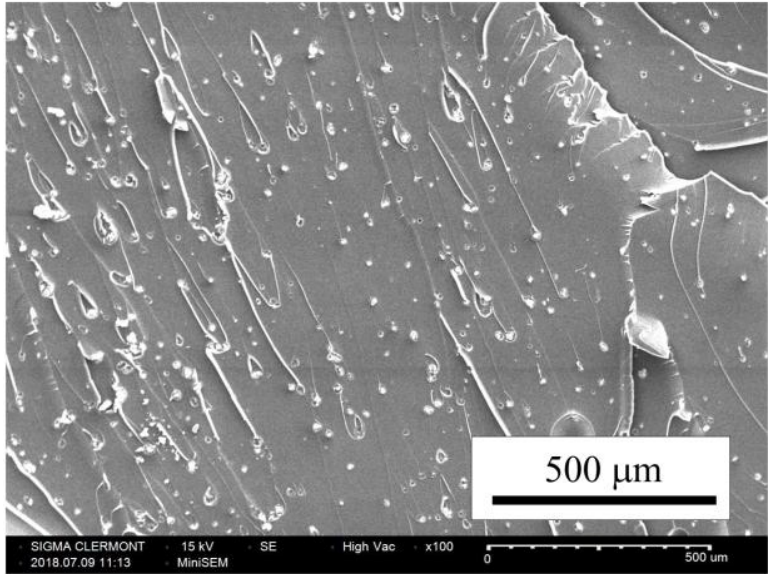

b)

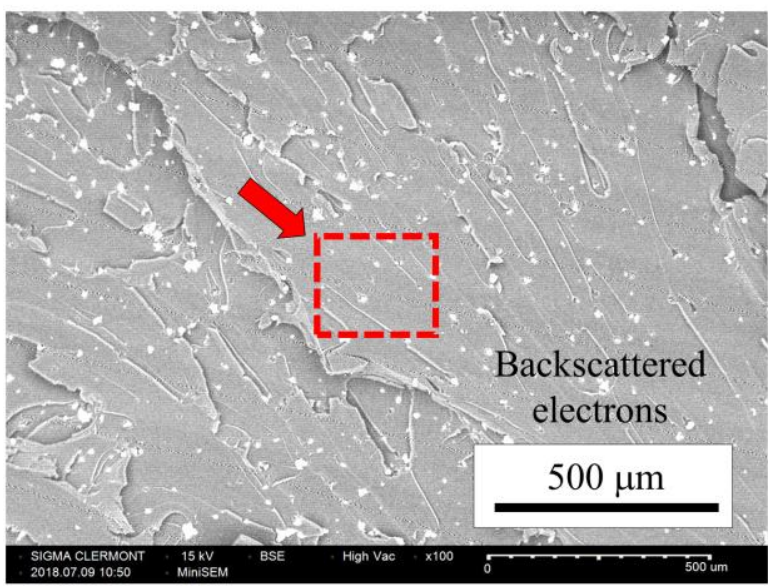

d)

Figure 7 Fractography analysis by SEM of the longitudinal specimens: a) non-ML specimen;

b) to d) ML specimen. Secondary electrons were used for images a to $\mathbf{c}$ whereas backscattered electrons were used for image d. 


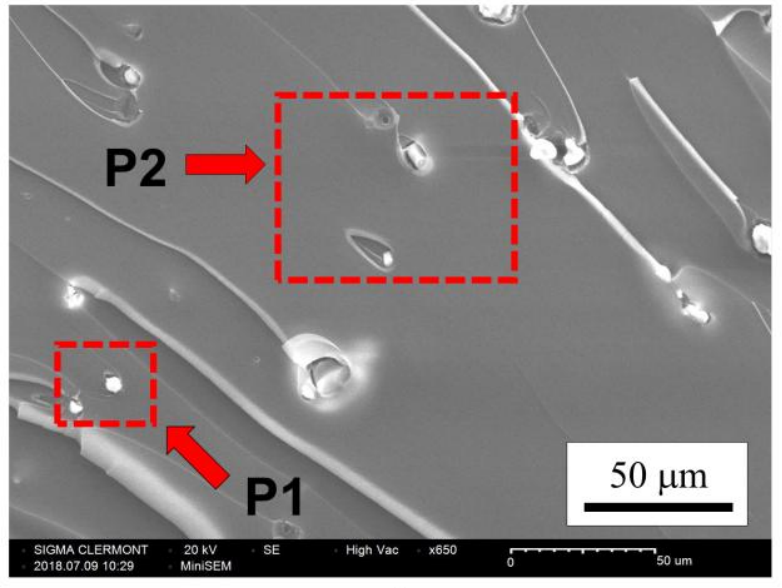

a)

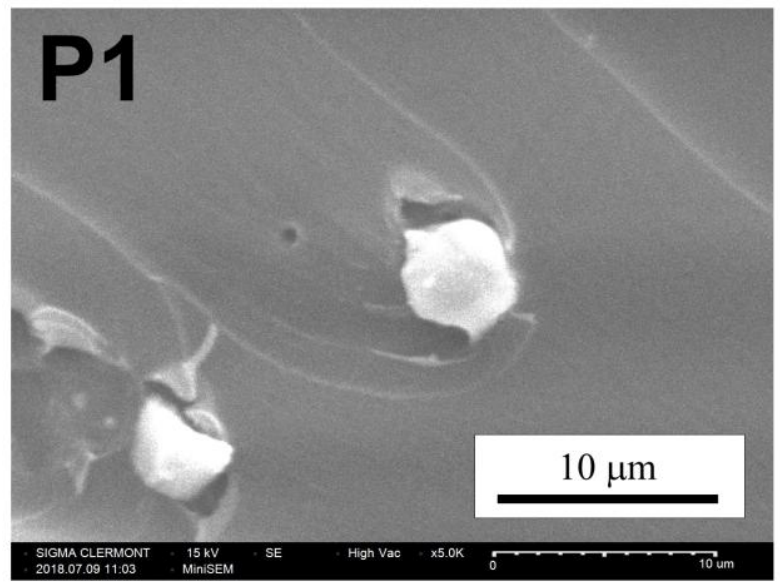

c)

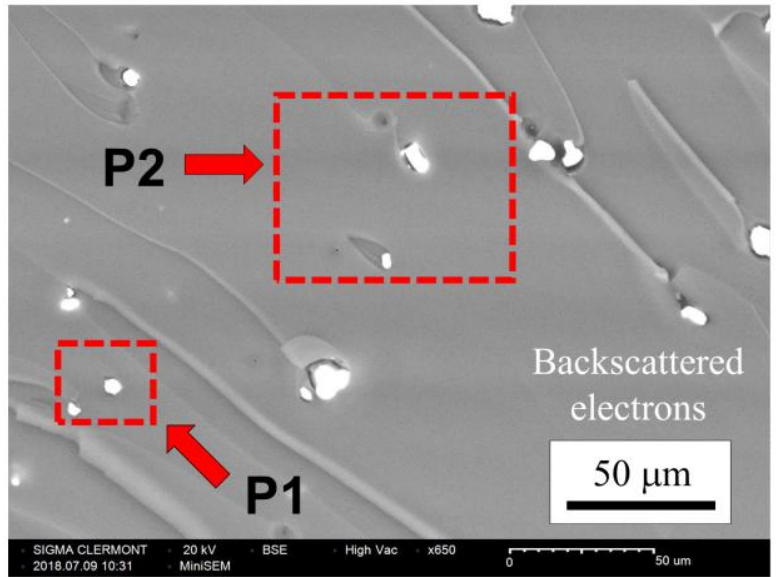

b)

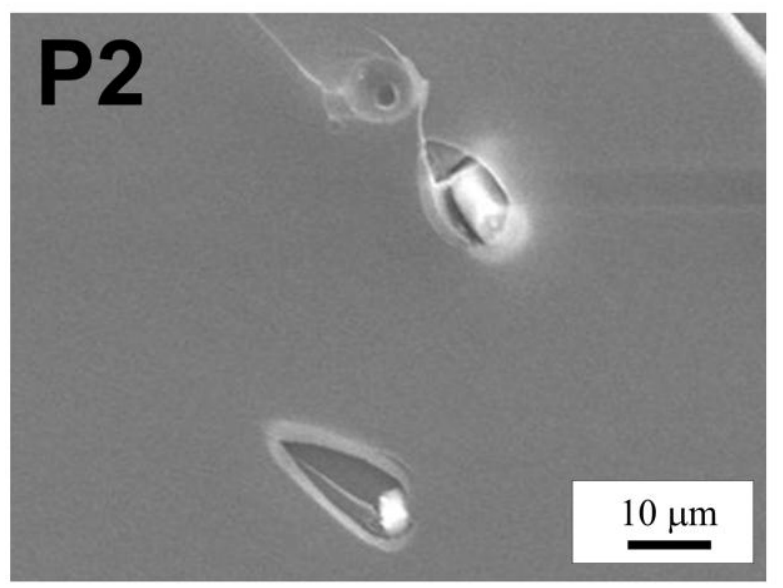

d)

Figure 8 Fractography analysis by SEM of the ML longitudinal specimen. Images a, $\mathbf{c}$ and $\mathbf{d}$ were obtained using secondary electrons whereas image $\mathbf{b}$ was obtained using backscattered electrons. 
a)

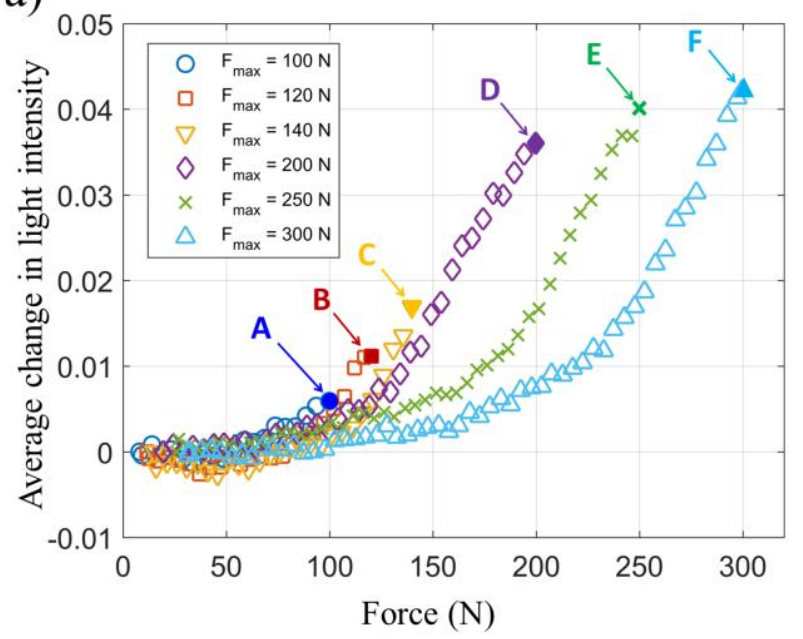

b)

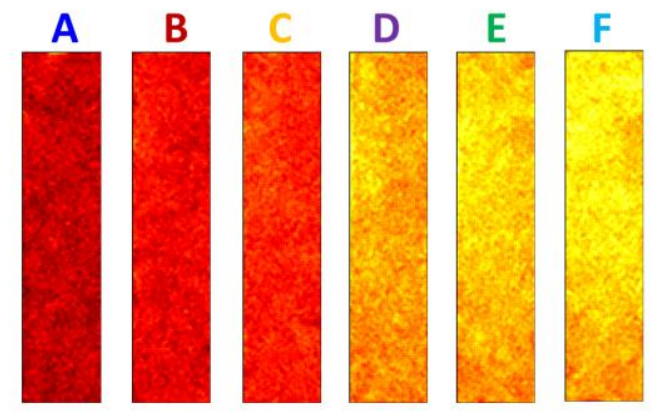

Change in light intensity

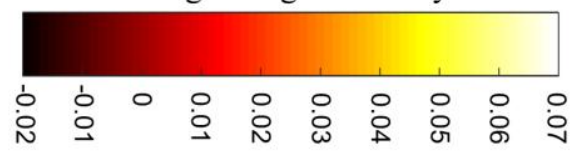

Figure 9 Light emission during the loading stages in uniaxial tension: a) variation in average light emission for the different loading stages of the ML specimen; b) maps of light emission at the maximum force of each loading phase in the zone of interest of the specimen. 


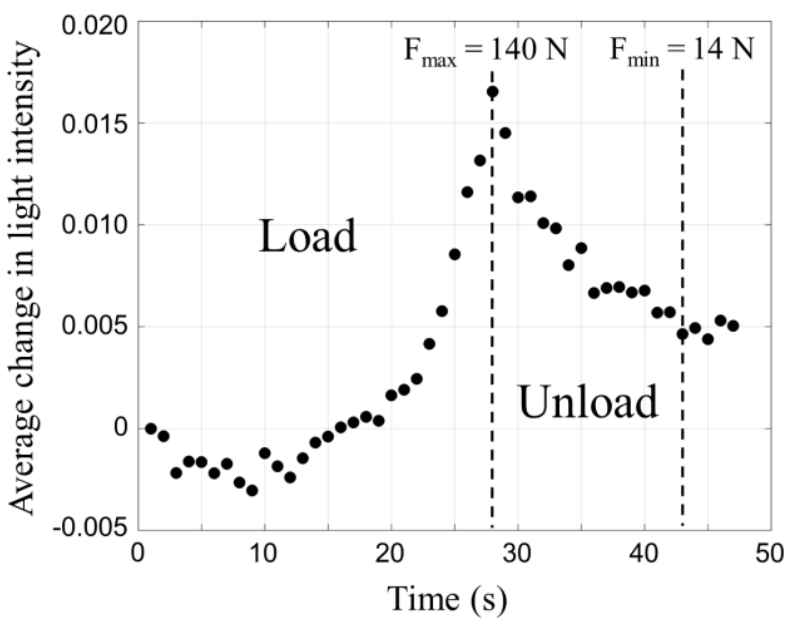

Figure 10 Light emission during a loading-unloading cycle (for $F_{\max }=140 \mathrm{~N}$ ) of the longitudinal ML specimen in uniaxial tension. 

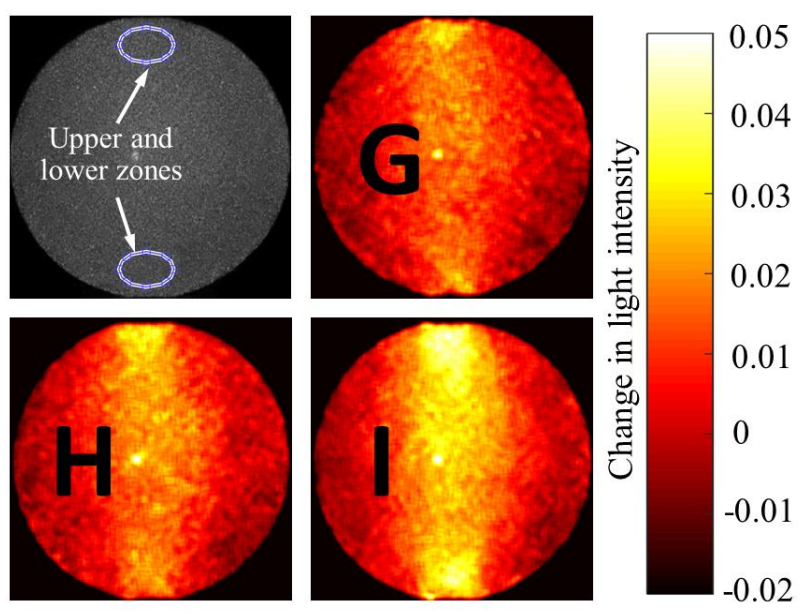

a)

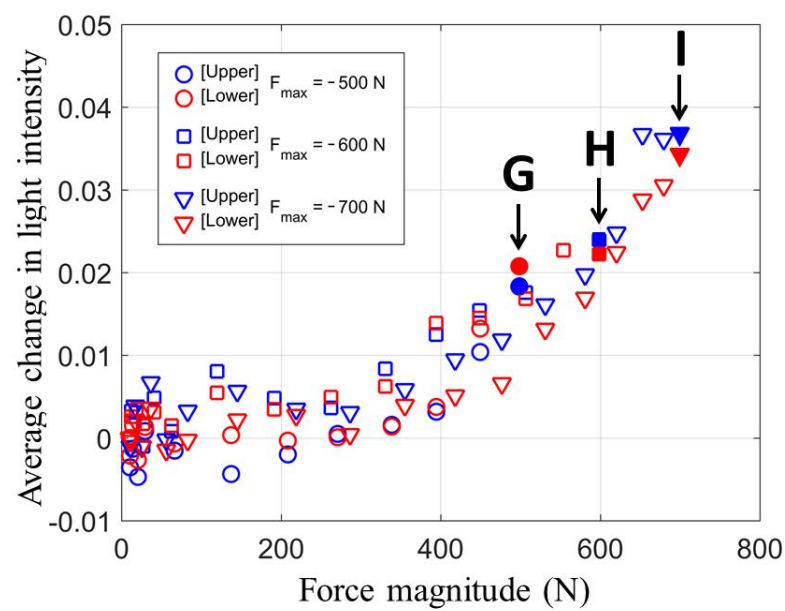

b)

Figure 11 Radial compression of a ML cylinder: a) maps of light emission for three loadings: $F_{\max }=-500 \mathrm{~N},-600 \mathrm{~N}$ and $-700 \mathrm{~N}$; b) variation in average light emission over two small zones close to the contacts during the loadings. 

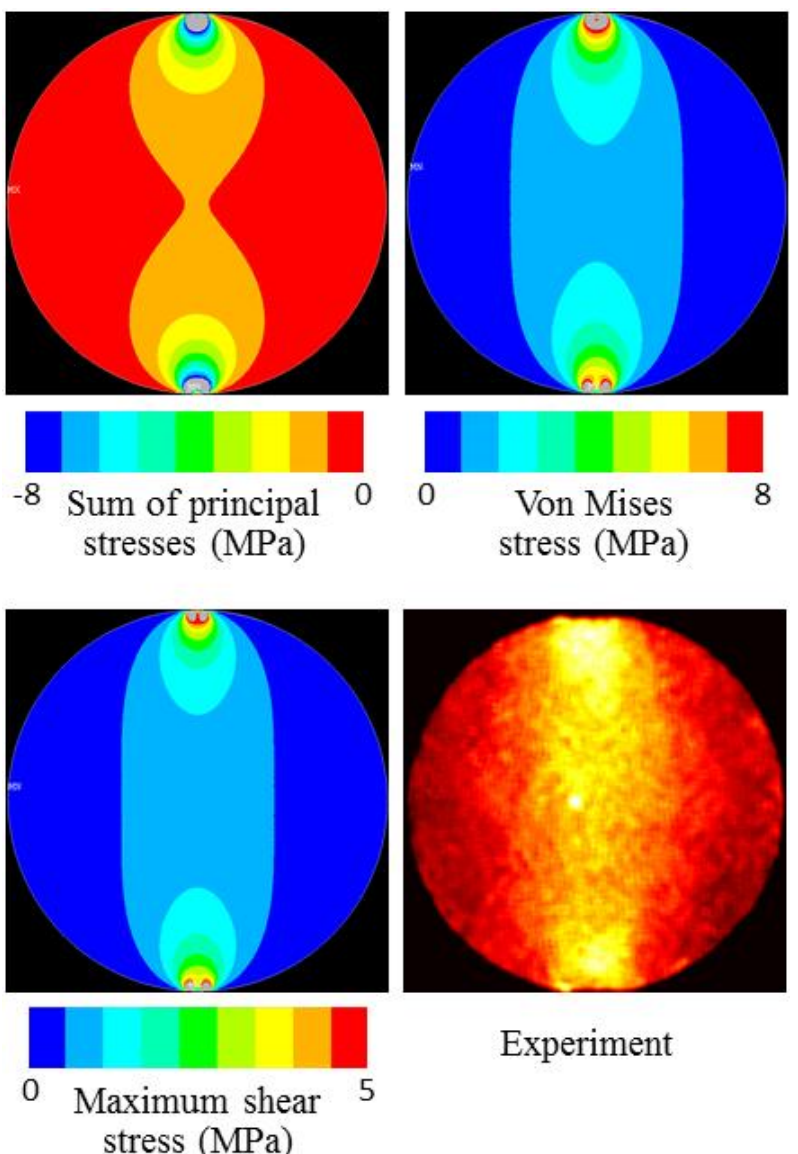

Experiment stress $(\mathrm{MPa})$

Figure 12 Radial compression of a cylinder: comparison between finite element simulation and experimental result. 


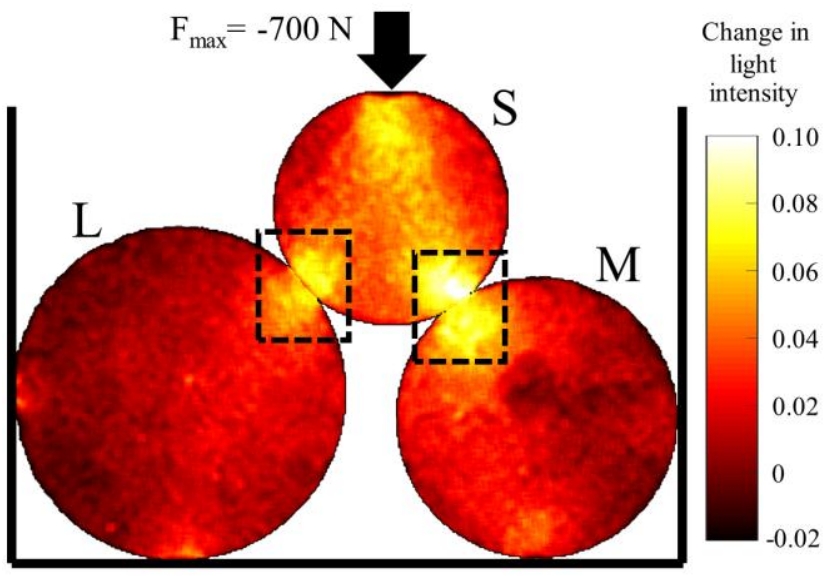

a)

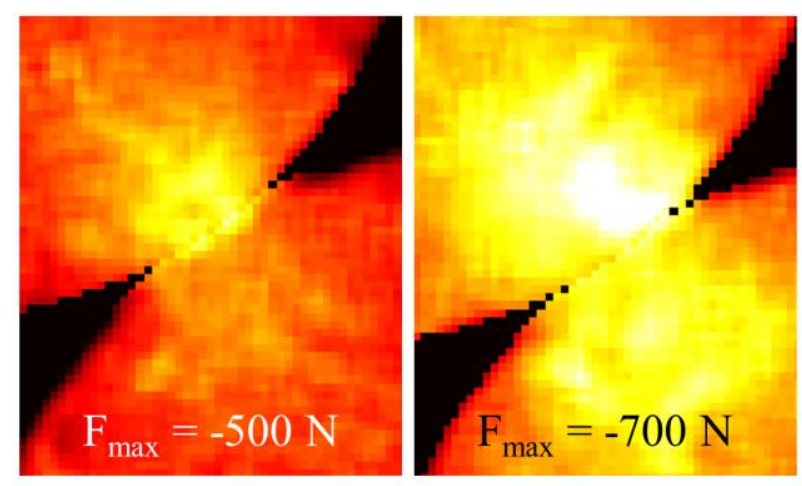

c)

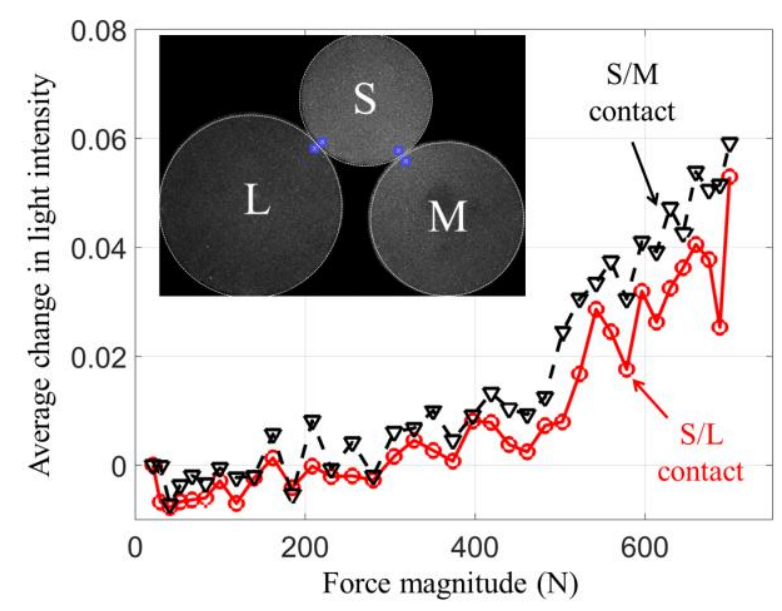

b)
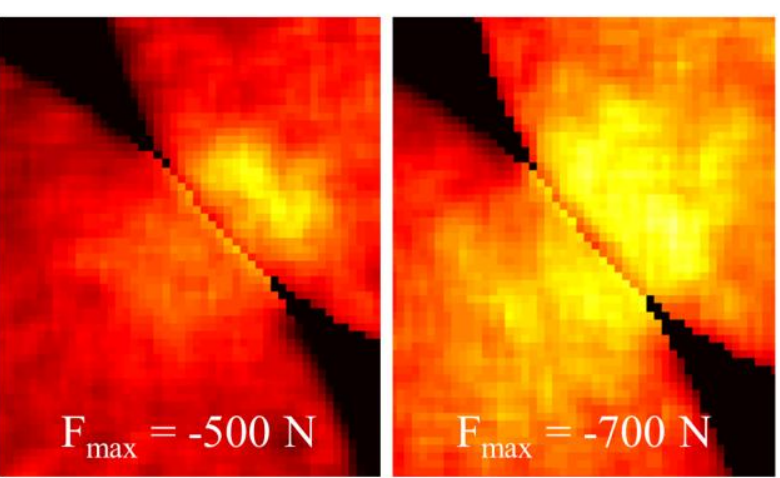

d)

Figure 13 Confined compression of three ML cylinders: a) light emission under $F_{\max }=-700$

$\mathrm{N}, \mathrm{b}$ ) variation in average light emission in the cylinder-cylinder contact zones during compression as a function of the vertical force until $F_{\max }=-700 \mathrm{~N}, \mathrm{c}$ ) close-up of the contact zone between small-medium cylinders, d) close-up of the contact zone between small-large cylinders, 


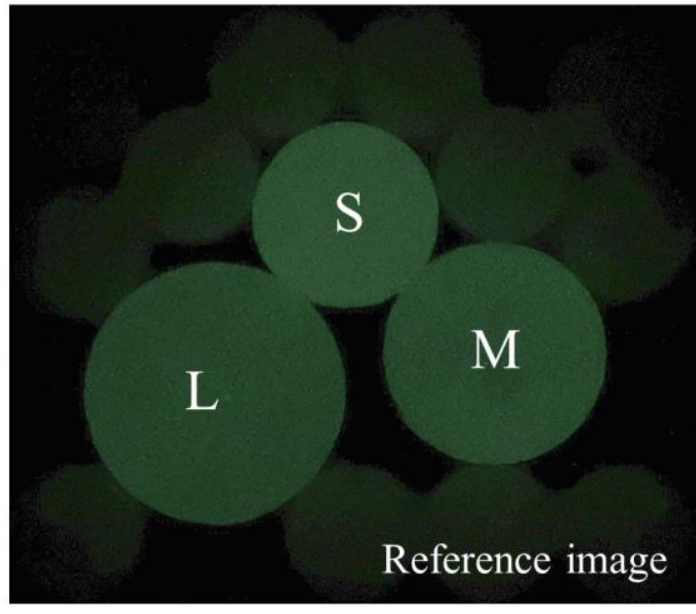

a)

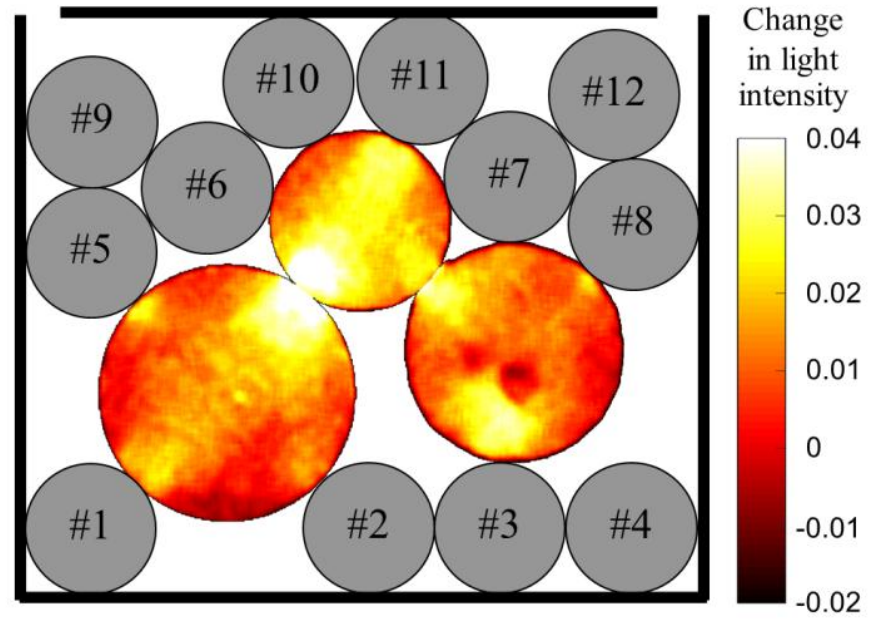

b)

Figure 14 Confined compression of fifteen cylinders among which three are ML: a) reference configuration; b) light emission under $-1500 \mathrm{~N}$. 